\title{
QUANTITATIVE FRACTOGRAPHY - WELL SPRING OF INTIMATE KNOWLEDGE IN FATIGUE CRACK GROWTH HISTORY
}

Quantitative fractography of fatigued structure parts can offer very useful and valuable information on the fatigue process. One of main contribution of this experimental method is a detailed description of fatigue crack growth in time and in space. The fractographic reconstitution of fatigue process history is conditioned by the existence and detectability of a fractographic feature characteristics of which is correlated with the fatigue crack growth rate. In the paper presented, three various fractographic features are used for the fractographic reconstitution striations (in the case of constant amplitude loading), beach marks (for simple program loading) and special inserted fracture marks (for complex program loading). All three methods described are illustrated on case studies, all from the area of testing and development of aircraft structure parts.

\section{Introduce}

Since long ago, the application of engineering materials has been accompanied by failures of structural parts, tools and other things which are made of them. Prevention of the failures the many of which have been catastrophic is conditioned by the development of effective failure analysis methods. The cost of failure analysis may exceed the value of the fractured part, but the cost of service failures usually far exceeds the cost of failure analysis [1]. For these purposes, fractography is undoubtedly the most effectual experimental method; it provides insights into the fracture process that are not accessible by any other means. Topography of fracture surface created by a growing crack is a result of interaction between material microstructure and service conditions, especially character of loading, temperature, environment etc. [2]. Information on a failure process is encoded in the fracture morphology. Main tasks of fractography is to decode this information, i.e., to find a correlation between identified fracture morphological features and corresponding physical processes which originated these features. Each fractographic features can be characterized by a set of qualitative and/or quantitative parameters. Qualitative parameters give fundamental information dealing with the fracture character (static or fatigue, brittle or ductile, transgranular or intergranular etc.) Quantitative parameters are measurable characteristics of fracture surface, e.g., the area percentage of the particular fractographic feature, its size (e.g., ductile dimple diameter, striation spacing, and cleavage facet size), local crack growth direction etc. A typical feature of current fractography is an effort to increase the mass of quantitative data supplying better and deeper understanding of the fracture processes and an integration of the experimental results with the theoretical knowledge of fracture mechanics.

Primary cause of a major part of all fractures in practice is material fatigue. One of the main contributions of quantitative fractography is the reconstitution of fatigue process history, i.e., setting of dependence of crack length (or other variable express- ing the failure extent) on the number of cycles (or on the other time related variable, e.g., service time, number of flights, etc.). The reconstitution is conditioned by the existence and detectability of a fractographic feature, some quantitative characteristic of which is corre- lated with the fatigue crack growth rate.

\section{Reconstitution of fatigue crack growth based on striation spacing measurements}

The most suitable fractographic features for a detailed description of fatigue crack growth are striations. If it is possible to distinguish individual striations and to measure their spacing, then the reconstitution of the fatigue process can be done very thoroughly, even cycle by cycle. The methods of this fractographic reconstitution developed at our department are described in detail in [3-5]. Results of the microfractographic measuring by means of a scanning electron microscope are usually presented in the form of dependence of the striation spacing (denoted s) on the crack length (denoted a), i.e., $s=s(a)$. Next processing of the experimental data set $\left(s_{i}\right.$, $\left.a_{i}\right), i=1,2, \ldots, k$, consists of two steps:

a) Transformation from a micro volume into a macro volume, i.e., conversion of the striation spacing (giving the information about the fatigue crack growth rate in the micro volume) into the macroscopic crack growth rate which is crucial quantity for the evaluation of fatigue life and loading capacity of the fatigued body.

b) Transformation of the dependence on the space coordinate (i.e., on the crack length $a$ ) into the functionality on a timedependent variables expressing the service time (e.g., number of loading cycles $N$ ).

The decisive problem of the first step is the relation between striation spacing $\mathrm{s}$ and the macroscopic crack growth rate $v=d a / d N$ [5]. These two variables are not generally identical; the equality

\footnotetext{
* Jiří Kunz, Jan Siegl, Ivan Nedbal

Department of Materials, Faculty of Nuclear Sciences and Physical Engineering, Czech Technical University in Prague, Trojanova 13,

12000 Prague 2, Czech Republic, E-mail: jiri.kunz@fjfi.cvut.cz
} 
$v=s$ is valid only under special conditions depending namely on the stress and strain field around the crack tip, temperature etc. The ratio $D=v / s$ is a function of the stress intensity factor range $\Delta K$ and it can vary within several orders (approximately, $10^{-3}<$ $<D<10^{1}$ ); it is influenced by the following phenomena:

1) discontinuous propagation of a fatigue crack front both in time and space, or in other words, existence of the so called "idle cycles",

2) deviation of local directions of a fatigue crack growth from a macroscopic one,

3) synergy of striation formation micromechanism with other ones, e.g., ductile dimple fracture, inter crystalline decohesion, quasi cleavage, etc.

The relation between striation spacing and the macroscopic crack growth rate $D$ must be a priori known or experimentally determined. For practical application of the suggested reconstitution technique, preferably the form $D=D(s)$ (i.e., $D$-factor as a function of striation spacing $s$ ) making possible to use a simple fundamental equation

$$
N_{x}=\int_{a_{i}}^{a_{x}} \frac{d a}{D(s) \cdot s(a)}+N_{i},
$$

where the number of cycles $N_{x}$ corresponds to the given crack length $a_{x}$, and $\left(N_{i}, a_{i}\right)$ is a priori known or determined couple of corresponding data, e.g., the total elapsed number of cycles, and crack length corresponding to the boundary between fatigue and final fracture.

An application of the method mentioned will be illustrated on the following case study: During the full-scale fatigue test, a model specimen of a wing spar of a small transport airplane was loaded by cyclic four-point bending with a constant amplitude [7]. The thin web plate was riveted to the L-profile flange plates. All the main structural components were made of $\mathrm{AlCu} 4 \mathrm{Mg} 1$ alloy type 2124. The fatigue test was finished after $N=117500$ applied loading cycles.

The fatigue cracks under study initiated in the hole of rivets connecting the spar web and the lower flange plate. The critical area is presented in Fig.1. During the full-scale test, the crack propagating upwards in the spar web was optically monitored. In the first period of the test, when the flange plate covered the crack

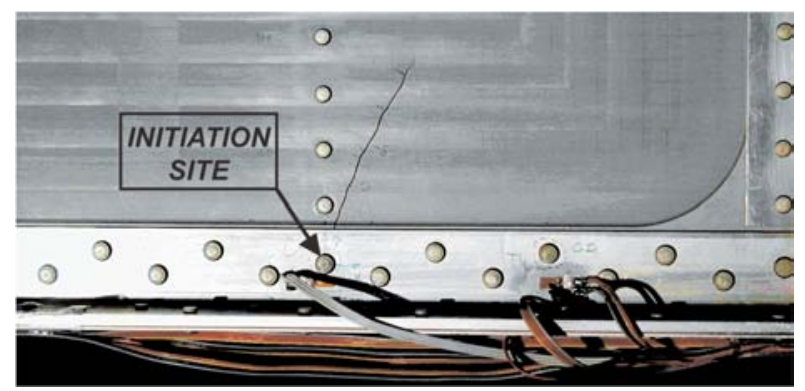

Fig. 1. Detail of critical area of wing spar - the studied fatigue crack in the spar web initiated on the rivet hole. The first period is covered by the lower flange plate. (see Fig.1), direct observation was impossible. This reason results in the fact that optical information on the crack growth in the web was available only in the last $42 \%$ of the test duration.

After the residual strength test and dismantling the tested wing spar, fracture surfaces were observed by means of a binocular light and scanning electron microscope. The limited set of macroscopic data on the fatigue crack propagation was completed by fractographic results [8]. Initiation of the fatigue crack in the rivet hole was of a multiple character. Regardless of the crack length, striations were a typical microfractographic feature. Striation spacing $\mathrm{s}$ was measured and presented as a function of the crack length a, where $\mathrm{a}$ is the distance of micro-area under study and rivet hole axis.

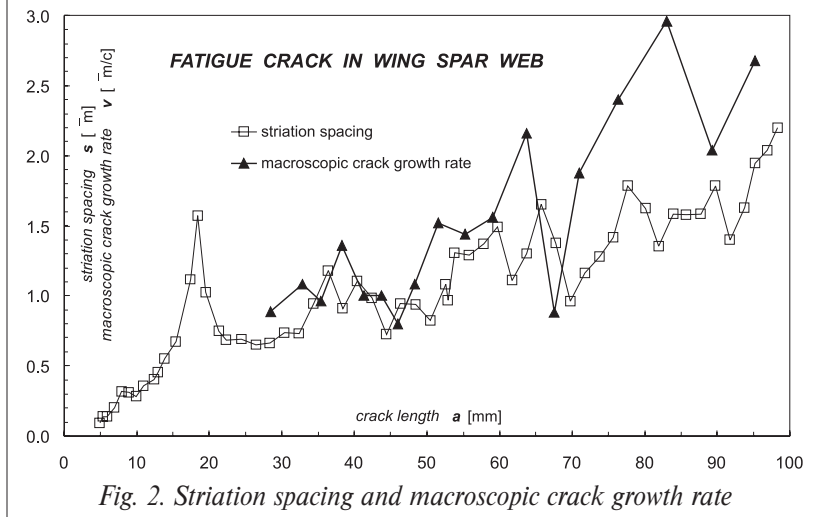

vs. crack length.

In Fig. 2, the microfractographic data $s=s(a)$ are compared with macroscopic crack growth rates $v=v(a)$ corresponding to the results of the direct optical monitoring. This comparison is in accordance with general experience [5] - in the range of the middle crack length, equation $v=s$ may be approximately acceptable, while for longer cracks, inequality $v>s$ is obvious.

Microfractographic data set $\left(s_{i}, a_{i}\right), i=1,2, \ldots, k$, was used for the reconstitution of the fatigue crack growth process history. Precision and exactness of the reconstitution results strongly depend on the volume and quality of input information. The fractographic reconstitution of the fatigue crack growth in the spar web was based on the knowledge of the empirical relation $D=D(s)$

$$
D(s)=1.797 \cdot 10^{45} \frac{s^{0.1108}}{(79.55-s)^{23.84}}
$$$$
\text { for }(0.09 \leq s \leq 4.74) \mu \mathrm{m} \text {, }
$$

determined by our previous laboratory experiments of similar Alalloy [5]. The results obtained are in a very good agreement with the macroscopic data - see Fig. 3.

For comparison, the results of the fractographic reconstitution based on a widely used but usually not verified assumption $v=s$, i.e. $D=1$, are presented in the same graph; in this case, the agree- 


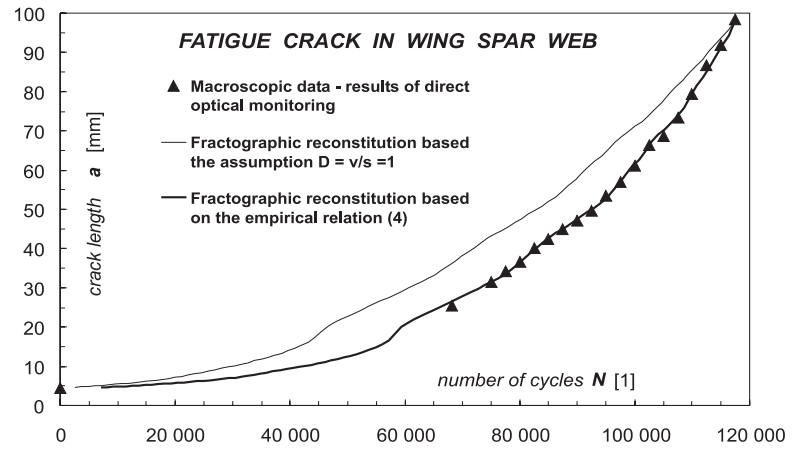

Fig. 3. Comparison of fractographic reconstitution of fatigue crack growth curve with macroscopic data.

ment of the reconstitution results with the macroscopic data is very poor (Fig. 3). In the both cases of fractographic reconstitution, the couple of data $N_{f}=117500$ and $a_{f}=98.5 \mathrm{~mm}$ corresponding to the fatigue test termination, was used as the "initial condition" in the relation (1). Growth of the fatigue crack under study in the area inaccessible to a routine visual monitoring was also obtained by means of this fractographic reconstitution.

\section{Fractographic Reconstitution of Fatigue Crack Growth under Simple Program Spectrum Loading}

In the case of program loading spectrum, e.g., flight simulation loading, the reconstitution of a fatigue crack growth is based on a fractographic identification of morphological features created by specific inherent part of the spectrum (e.g., gust cycle, the most severe flight etc.). Spacing between two neighboring beach marks is equal to a crack length increment during the corresponding loading block. If the beach marks are readable and their spacing is measurable, neither marking nor special modification of original loading spectrum is needful. In this case, there is no trouble with the relation between a microscopic and macroscopic crack growth rate. The application of this method for fractographic reconstitution of a fatigue crack growth in aircraft structure parts is presented, e.g., in $[9,10]$.

In addition to the crack growth rate, observation of beach marks has been giving information on the crack front shape and

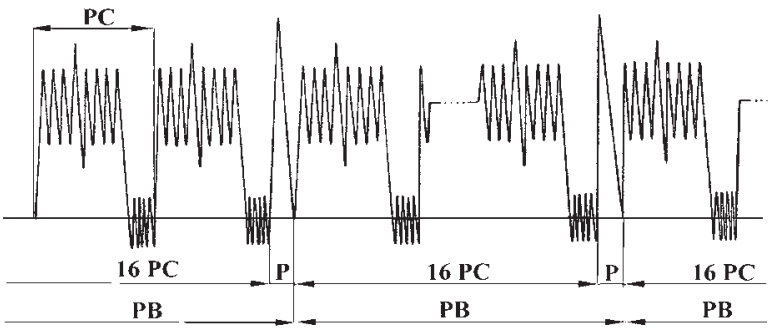

Fig. 4. Loading program used in full-scale test of L 410 UVP aircraft wing. its changes in time and space. On this base, two dimensional description of fatigue degradation of a body cross section is possible.

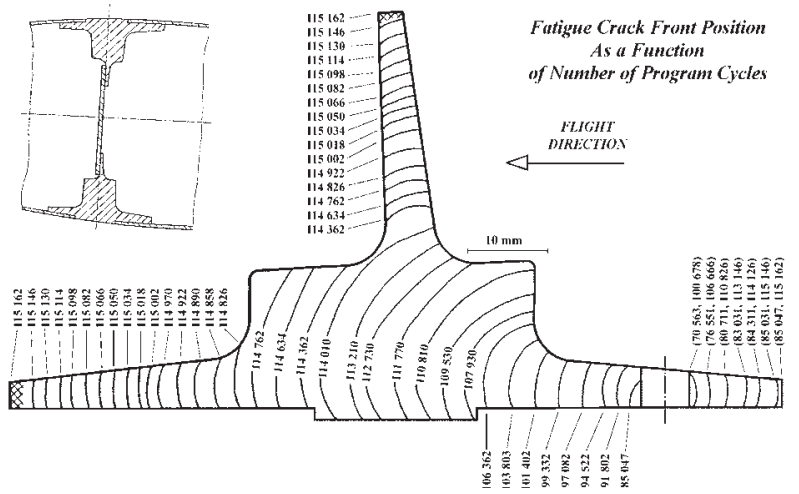

Fig. 5. Fractographic reconstitution of fatigue process in wing beam (loading program $P B=16 P C+P$ - see Fig. 4).

As an example, in the full-scale test of transport aircraft wing, the loading program block $(\mathrm{PB})$ consists of 16 program cycles (PC) simulating 16 flights and one severe cycle $(\mathrm{P})$ simulating the gust $6.8 \mathrm{~m} / \mathrm{s}$, was applied - see Fig.4 [11],[12]. The program block consists of 193 various cycles. Periodically repeated gust cycles resulted in microscopically detectable beach marks on fracture surfaces of the fatigued wing parts. The distance between two neighboring beach marks represents the fatigue crack increment during the one PB. The beach mark spacing $s_{p}$ as a function of fatigue crack length a was obtained by means of the quantitative fractographic analysis. On the base of the $s_{p}=s_{p}(a)$ relation, position and shape of the fatigue crack front in time (i.e., as a function of the overall applied number of program cycles) was determined e.g., see Fig. 5.

\section{Fractographic Reconstitution of Fatigue Crack Growth Based on Fracture Marking by Special Cycles Inserted into the Complex Program Loading Spectrum}

In the case of real structures tested under the complex loading spectrum (i.e., flight by flight, random etc.), a sophisticated method of fatigue fracture marking has to be applied. As an example, a full-scale fatigue test of the main beam of fighter body will be given [13]. Service conditions were simulated by means of a flightby-flight loading spectrum. The applied complex loading spectrum consists of many cycles with a very different amplitude. This fact disables fractographic reconstitution of the fatigue crack process based on the striation spacing measurements. Therefore, special coded marking loading blocks were applied in the test. One marking set consists of 12 different marks symbols of which are given in the table in Fig. 6.

The symbols used are similar to Morse code: the "dot" consists of 100 constant amplitude cycles, the "dash" consists of the same 800 cycles. Individual "dots" and "dashes" were separated by 


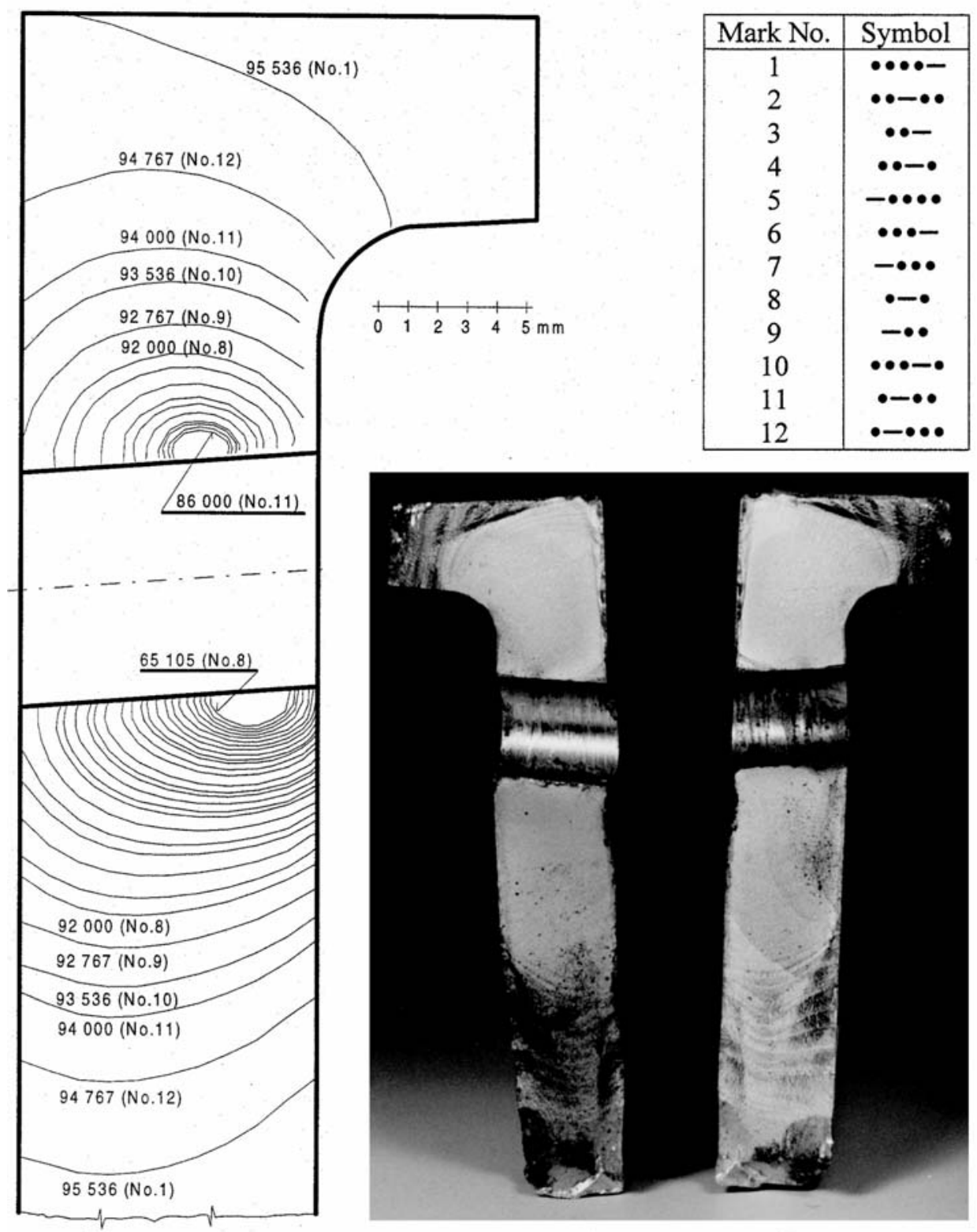

Fig. 6. Fractographic reconstitution of fatigue crack growth in a main beam based on the coded fracture marking introduced during the full-scale test of the fighter body. Results are presented as a function of SFH number.

a special cycle with a higher stress amplitude. In one marking set there is no problem with identifying individual marks; therefore, each mark differs from each other and thus it is unequivocal. Even in the case of difficulty with direct identification of some mark, there is a possibility to use a second level of information, i.e., to define it more precisely by means of identification of the neighbouring (i.e., the last before and next after) marks because the sequence of the individual marks is constant and known. The same marking set is repeatedly applied during the full-scale fatigue test.

The results of fractographic analysis of the main beam fracture are summarized in Fig. 6, where a two-dimensional description of fatigue process as a function of simulated flying hours
$(\mathrm{SFH})$ is presented. Both fatigue cracks under study initiated on the screw hole. The detailed fractographic analysis revealed the shape and position of the fatigue crack fronts corresponding to individual marks applied during the full-scale test in the time interval between 65105 and $95536 \mathrm{SFH}$. Examples of fractographic mark No. 1 on the fracture surface are presented in microfractograph in Fig. 7.

\section{Conclusions}

Methods of fractographic reconstitution of a fatigue crack growth are very useful especially in the failure analysis of struc- 


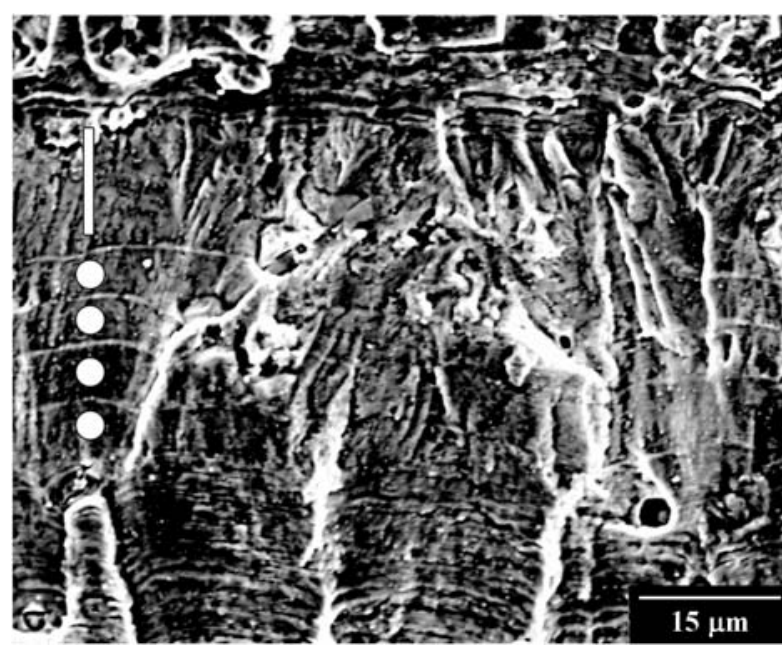

Fig. 7. Microfractograph of mark No.1 on the fighter main beam fracture.

tural components fatigued during the full scale tests or service. Methods of fractographic reconstitution are illustrated on three case studies focused on the area of aircraft structure testing and developments. In the first case, a model specimen of the aircraft wing spar was loaded at a constant stress amplitude and fractographic reconstitution was based on the striation spacing measurements. In the second one, during a full-scale test of the transport aircraft wing, the simple program block consists of 16 program cycles simulating 16 flights and one severe cycle simulating the gust was applied. Periodically repeated gust cycles resulted in beach marks on the fracture surfaces; fractographic reconstitution was based on the measuring of a beach mark spacing. In the third case study, the main beam of the fighter fuselage was tested under a complex (flight by flight) loading spectrum. In this fatigue test, special coded marking loading blocks were applied and fractographic reconstitution was based on the identification of corresponding marks on the fracture surface.

The results obtained represent a very reliable output to describe the fatigue process in time and/or in space, i.e., the invaluable information often unattainable by any other means.

This research has been supported by project MSM6840770021 "Diagnostic of Materials".

\section{References}

[1] PARRINGTON, R. J.: Fractography of Metals and Plastics. Practical Failure Analysis, 2, 2002, No.5, pp. 16-46.

[2] HULL, D.: Fractography. Observing, Measuring and Interpreting Fracture Surface Topography. Cambridge University Press 1999,366 p.

[3] NEDBAL, I., SIEGL, J., KUNZ, J.: Fractographic Study of Fatigue Crack Kinetics in Bodies and Structures. In: Advances in Fracture Research 84 (Proc. ICF 6, New Delhi). Eds. S.R. Valluri et al. Vol. III. Oxford, Pergamon Press 1984, pp. 2033-2040.

[4] NEDBAL, I., KUNZ, J., SIEGL, J.: Quantitative Fractography - Possibilities and Applications in Aircraft Research. In: Basic Mechanisms in Fatigue of Materials (Proc. Int. Colloq., Brno). Materials Science Monographs, 46. Eds. P. Lukáš, and J. Polák. Amsterdam, Elsevier 1988, pp. 393-403.

[5] NEDBAL, I., SIEGL, J., KUNZ, J.: Relation between Striation Spacing and Fatigue Crack Growth Rate in Al-Alloy Sheets. In: Advances in Fracture Research (Proc. ICF 7, Houston). Eds. K. Salama et al. Vol.5. Oxford, Pergamon Press 1989, pp.3483-3491.

[6] NEDBAL, I., KUNZ, J., SIEGL, J.: Microfractographic Aspects of Fatigue Crack Growth in 7010 Aluminium Alloy. In: Fractography '97 (Proc. Int. Conf., Stará Lesná). Ed. L. Parilák. Košice, IMR SAS 1997, pp. 264-270.

[7] AUGUSTIN, P., PÍŠTĚK, A.: Experimental Data Determination for the Damage Tolerance Analysis of the Wing Spar with Cracked Web. In: Proc. EAN 2000 (38th Int. Conf. Experimental Stress Analysis, Třešt), 2000, pp. 9-14.

[8] KUNZ, J., SIEGL, J., NEDBAL, I., AUGUSTIN, P., PÍŠTĚK, A.: Application of Quantitative Microfractography in Damage-Tolerance and Fatigue Evaluation of Wing Spar. In: Proc. 24th International Congress of the Aeronautical Sciences (ICAS 2004, Yokohama). Ed. I. Grant. Edinburgh, Optimage Ltd., 2004, 10 p., CD-Rom.

[9] SIEGL, J., SCHIJVE, J., PADMADINATA, U. H.: Comparison of Fractographic Observation Results and Predictions for MiniTWIST Flight Simulation Loading. Int. J. Fatigue, 13, 1991, No.2, pp. 139-147.

[10] KUNZ, J., NEDBAL, I., SIEGL, J.: Application of Fractography in Full-Scale Tests of Aircraft Structure Parts. In: Fracture Behaviour and Design of Materials and Structures (Proc. ECF 8, Torino). Ed. D. Firrao. Vol. III. Cradley Heath, EMAS 1990, pp. 1662-1669.

[11] HRKAL, K., RŮŽIČKA, M.: Life test of wing of aeroplane L 410 UVP - II. (in Czech), [Technical report VZLÚ Z-2694/82.] Praha, VZLÚ 1982, $237 \mathrm{p}$.

[12] HRKAL, K., RŮŽIČKA, M.: Life test of wing of aeroplane L 410 UVP - II. Annex 1. (in Czech) [Technical report VZLÚ Z-2694/82.] Praha, VZLÚ 1983, $78 \mathrm{~s}$.

[13] NEDBAL, I., KUNZ, J., SIEGL, J.: Some Remarks on Fatigue Fracture Marking. In: Fatigue '99 (Beijing). Vol. 4/4. Eds. X.R. Wu, and Z.G. Wang. Beijing - Cradley Heath, HEP - EMAS 1999, pp. 2373-2378. 